\title{
Standard Reference Material (SRM) 482: A Metallographic Challenge
}

\author{
E.S. Windsor*, R.A. Carlton**, S.A. Wight*, and G. Gillen* \\ *Surface and Microanalysis Science Division, National Institute of Standards and \\ Technology, Gaithersburg, MD 20899 \\ **Elan Pharmaceuticals, King of Prussia, PA 19406
}

The National Bureau of Standards issued standard Reference Material (SRM) 482 in 1969 as a standard for use in electron probe microanalysis (EPMA) [1]. SRM 482 is a set of six wires, each approximately $5 \mathrm{~cm}$ long and $0.5 \mathrm{~mm}$ in diameter. The set represents the copper-gold binary alloy system and contains one wire of each of the following compositions (weight percentage): pure copper $(\mathrm{Cu})$, pure gold $(\mathrm{Au}), \mathrm{Cu} 80 \mathrm{Au} 20$, $\mathrm{Cu} 60 \mathrm{Au} 40, \mathrm{Cu} 40 \mathrm{Au} 60$, and $\mathrm{Cu} 20 \mathrm{Au} 80$. Even though SRM482 was issued 33 years ago, metallographic preparation of these wires still presents challenges today.

Sample preparation of soft metals has challenged metallographers for over a century. As a result, numerous clever techniques were developed to polish these materials. These techniques include electropolishing, electromechanical polishing, chemical polishing and chemical-mechanical (attack) polishing [2,3]. Although these techniques are useful when preparing samples for microstructure analysis, they are not recommend when preparing samples for microchemical analysis because they use reactive chemicals to polish or aid the polishing of the sample. These chemicals may alter the chemistry of the material itself. Generally, sample preparation for microanalysis is limited to mechanical techniques.

One of the first challenges encountered in the preparation of SRM 482 is to mount these wires into a form suitable for microanalysis. Mounting irregularly shaped objects in epoxy is a technique that is used extensively in metallography. For SRM 482 however, we do not recommend this procedure. Epoxy is an electrically insulating material and unless a conductive path to ground (i.e. the sample holder) is provided, these wires will charge when analyzed in the electron beam. A standard procedure to eliminate charging is to deposit a thin layer of carbon over the surface of the sample. Unfortunately, this procedure does not always eliminate charging but sometimes reduces it to a level not readily detected by the unsuspecting analyst. Data collected under these conditions may be in error. To solve this problem, we press fit the wires into holes drilled in a conductive aluminum block.

Recently, blemishes were observed on the polished surface of the Cu80Au20 and the Cu40-Au60 wires (figure 1) [4,5]. Normally, this might not be considered unusual, but since SRM 482 was painstakingly prepared, extensively analyzed and certified to be microscopically homogeneous [6], their occurrence raised some interesting concernsas to what these features are and why they have not been previously reported. Sample preparation experiments have demonstrated that these features are observed when the wires are polished $(0.25 \mu \mathrm{m}$ diamond or $0.05 \mu \mathrm{m}$ alumina $)$ on napped cloths. But, they are not observed when the wires are finished $(0.25 \mu \mathrm{m}$ diamond $)$ on a chemotextile cloth. At 
first, we thought these features were artifacts resulting from the use of napped cloths during final polishing but, subsequent analysis using secondary ion mass spectroscopy (SIMS) proved them to be oxide inclusions present within the wire itself.

Other problems encountered during the metallographic preparation of SRM 482 include impressed abrasives and the smearing of soft metal components. Figure 2 shows diamond abrasives impressed into the surface of a gold wire that was polished with $0.25 \mu \mathrm{m}$ diamond suspension on a chemotextile cloth. Electron probe microanalysis of the gold end member wire often reveals the presence of copper. This indicates that smearing is occurring between wires during sample preparation.

In conclusion, preparation of SRM 482 for microanalysis is not trivial. Both metallographer and analyst alike need to be aware of problems that exist in the preparation and use of these wires as standards for microanalysis. Currently, we are developing a recommended procedure and some guidelines for the use of SRM 482. We plan on appending this information to the Certificate of Analysis.

\section{References}

[1] Certificate of Analysis: Standard Reference Material 482 (1969).

[2] G.F. Vander Voort, Metallography Principles and Practice, ASM International, Ohio, 1999.

[3] L.E. Samuels, Metallographic Polishing by Mechanical Methods, Third edition, ASM, Ohio, 1985.

[4] R.A. Carlton, Ph.D. Thesis, Lehigh University, 2001.

[5] E.S. Windsor et al., Proc. Microsc. and Microanal. 7 (Suppl. 2)(2001) 678.

[6] Heinrich, K. F. J., et al., NBS Special Publication 260-28 (1971).

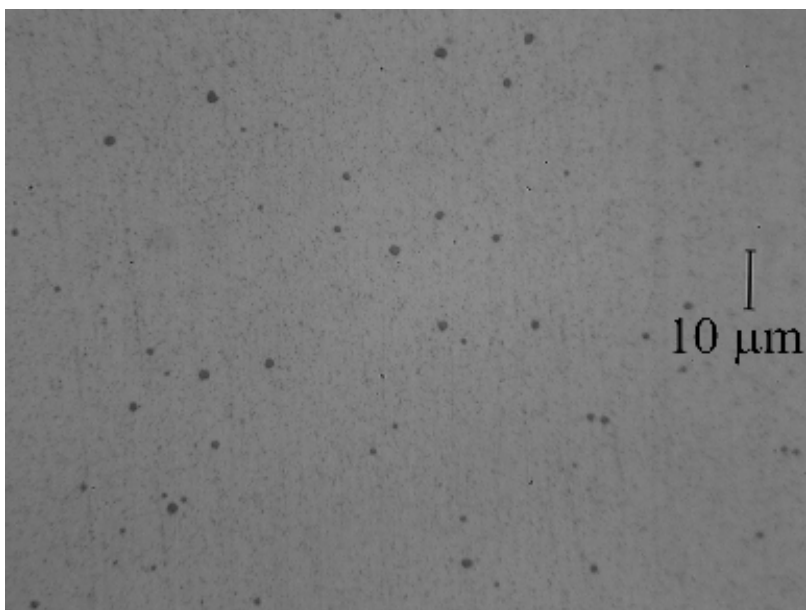

Figure 1

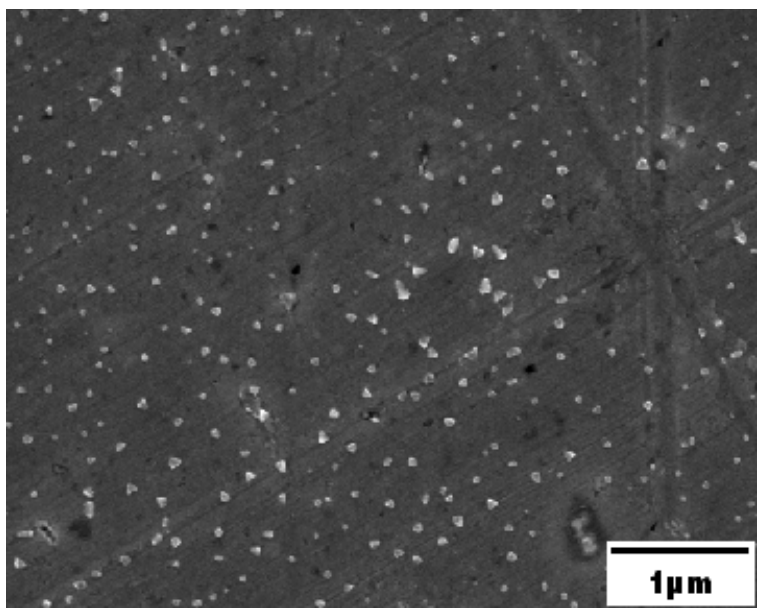

Figure 2

FIG. 1. Light micrograph showing oxide inclusions in Cu80-Au20 wire.

FIG. 2. Secondary electron image showing impressed diamond abrasive on the surface of the gold wire. Wire was polished with $0.25 \mu \mathrm{m}$ diamond suspension on a chemotextile cloth. 